\title{
An efficient asymmetric synthesis of Enigmols (1-deoxy-5- hydroxysphingoid bases), an important class of bioactive lipid modulators
}

\author{
Anatoliy S. Bushnev, ${ }^{\text {a }}$ Mark T. Baillie, ${ }^{\text {a }}$ Jason J. Holt, ${ }^{\mathrm{c}}$ David S Menaldino, ${ }^{\mathrm{a}}$ Alfred H. \\ Merrill Jr., and Dennis C. Liotta ${ }^{\mathrm{a}, \mathrm{c}^{*}}$ \\ ${ }^{a}$ Department of Chemistry, Emory University, 1515 Dickey Dr, Atlanta, GA 30322, USA \\ ${ }^{b}$ School of Biology, Georgia Institute of Technology, Atlanta, GA 30332, USA \\ ${ }^{c}$ Emory Institute for Drug Discovery (EIDD), 1515 Dickey Dr, Atlanta, GA 30322, USA \\ E-mail:dliotta@emory.edu
}

\begin{abstract}
An enantioselective synthesis of the four 2S-diastereomers of enigmol (2-amino-octadecane-3,5diols) from $L$-alanine is reported. The procedure described is robust, highly stereoselective at each step, and suitable for preparation of gram quantities of material.
\end{abstract}

Keywords: Enigmols, sphingolipids, boron enolates, aldol reaction, 1-deoxysphingoid bases

\section{Introduction}

Sphingolipids (ceramides, sphingomyelins, cerebrosides, gangliosides, etc.) are a structurally diverse class of complex membrane lipids, composed of long-chain 2-amino-1,3-diols (sphingoid bases), amide-linked fatty acids, and numerous phosphoric acid and carbohydrate polar head groups, connected to the primary hydroxyl. Studies performed over the past two decades have shown that the low molecular weight sphingolipid metabolites (ceramide 3, sphingosine 4, sphingosine 1-phosphate (S1P, 5)) are involved in many critical signaling pathways that regulate, inter alia, cell growth, cell differentiation and apoptosis. ${ }^{1}$ Furthermore, sphingolipids function as modulators for growth factor receptors and as second messengers for a growing list of agonists. ${ }^{1,2}$

Sphingolipid modulators are now emerging as potential therapeutics, and the first candidates targeting S1P signaling have just begun to come on to the market. For example, the Novartisdeveloped drug candidate Gilenia (previously Fingolimod) 6 just received FDA approval. This compound is a potent S1P antagonist and has shown to be beneficial to patients having relapsing multiple sclerosis in clinical studies. Similarly, safingol 7, an unnatural sphinganine diastereomer and potent sphingosine kinase inhibitor, has been shown to provide some benefit in breast cancer patients when used topically. ${ }^{5}$ 


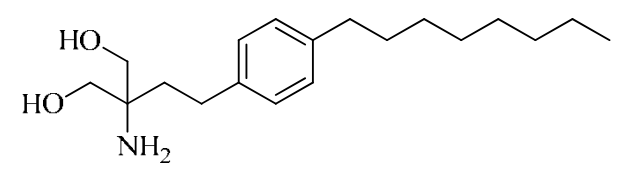

Gilenia (Fingolimod, 6)

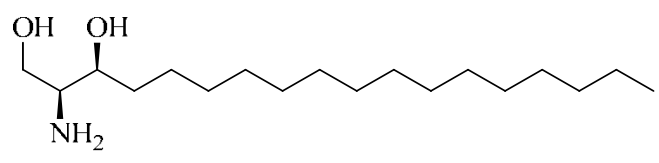

Safingol (7)

Figure 1

During the early stages of our own sphingolipid modulator program, we were intrigued by the apparent bifurcation in the biological functions of the sphingolipid biosynthesis products shown in Scheme 1.
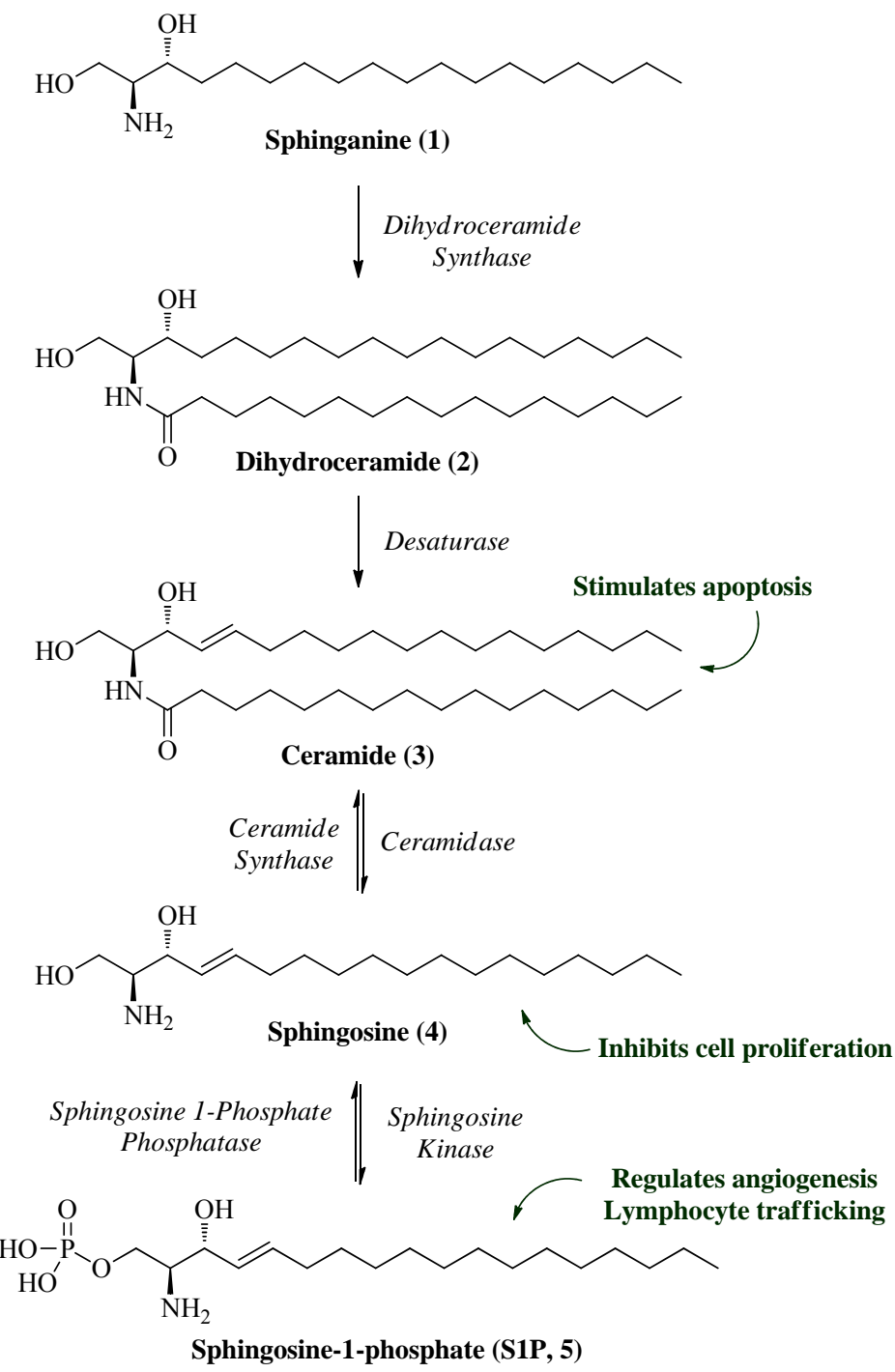

\section{Scheme 1}


Specifically, the sphingoid bases 1 and $\mathbf{4}$, as well as their amine metabolites ( $\mathrm{N}$-methylation and fatty acid $\mathrm{N}$-acylation adducts $\mathbf{2}$ and 3 ) appeared to promote anti-mitotic activity, while sphingosine-1-phosphate (S1P, 5) appeared to be pro-mitotic. ${ }^{1}$ Thus, from a structural perspective, phosphorylation of the C-1 hydroxyl group seemed to be the key differentiating element that resulted in two vastly different biological outcomes. Perhaps, we hypothesized, this observation could serve as the basis for designing sphingoid base analogs that could only elicit anti-mitotic behavior. The attractiveness of this proposal was enhanced by the knowledge that 1deoxy sphingoid bases could not be substrates for decomposition by sphingosine-1-phosphate lyase, and that 1-deoxysphinganine 9, an inhibitor of sphingosine kinase, lowers levels of endogenous S1P, thereby exerting an additional, albeit indirect, anti-mitotic effect.

While the conceptual excision of the C-1 hydroxyl group would likely achieve our goals from a mechanism of action perspective, we worried that removal of the hydroxyl group would convert an already "greasy" compound into an even more hydrophobic entity that would have poor drug-like properties. To circumvent this problem, we focused instead on compounds containing the 2-amino-3,5-diol head-group (later termed 'enigmols'), which would eliminate the pro-mitotic and anti-apoptotic properties of naturally occurring sphingoid bases without altering the overall hydrophobicity and (presumably) compartmentalization properties of the new analogs. Furthermore, the addition of a new chiral center at C-5 would allow us, in principle, to examine the biological properties of eight different stereoisomers (four pairs of diastereomers), thereby providing us with a straightforward approach for tuning the biological specificity of these compounds.
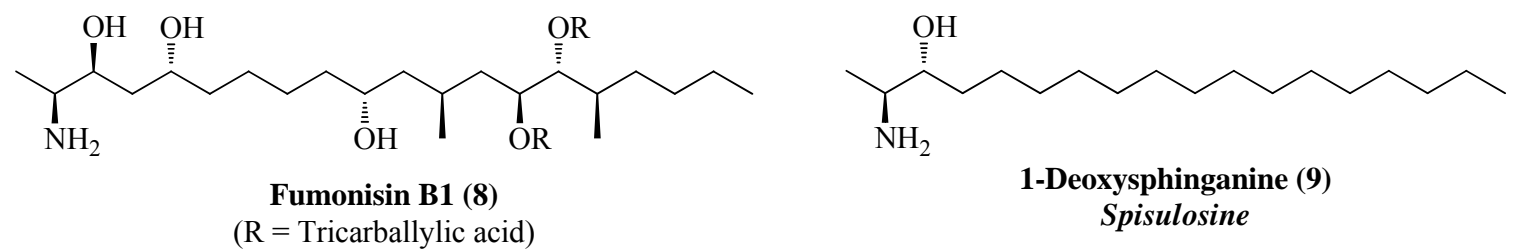

Figure 2

This potential utility of our design strategy was reinforced by the discovery of Fumonisin $\mathrm{B}_{1}$ 8, a naturally occurring mycotoxin produced by the fungus Fusarium moniliforme, that shares structural similarities to the sphingoid bases. ${ }^{6}$ Soon after its discovery, Fumonisin $\mathrm{B}_{1}$ was shown to be an inhibitor of ceramide synthase, a key enzyme in the sphingolipid biosynthetic pathway (see Scheme 1). ${ }^{7}$ Since addition of exogenous ceramide synthase inhibitors, like Fumonisin $B_{1}$, elevates the endogenous levels of sphingoid bases (primarily sphinganine) to toxic levels, this provided yet another mechanistic rationale for studying these compounds. ${ }^{8}$ 
<smiles>CCCCCCCC(O)CC(O)C(C)N</smiles>

$(2 S, 3 S, 5 S)-10$<smiles>CC(N)C(O)C[C@@H](O)c1ccccc1</smiles>

$(2 S, 3 S, 5 R)-11$

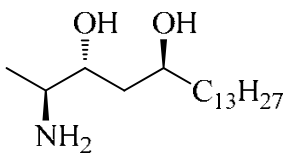

$(2 S, 3 R, 5 S)-12$

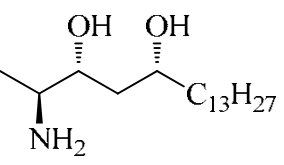

$(2 S, 3 R, 5 R)-13$

\section{Figure 3}

In the early 1990's, we performed the first total synthesis of the four $2 S$-enigmol diastereomers 10-13 as simplified structural analogs of Fumonisin $\mathrm{B}_{1}$, starting from $L$-alanine. ${ }^{9}$ While this route served its purpose, a more efficient synthesis was required to prepare larger quantities of each compound. Herein, we describe a scalable synthesis of 2S,3S,5S-enigmol 10 and its C-3 and C-5 diastereomers 11-13. The synthesis is centered around a highly diastereoselective boron-mediated aldol reaction, which is a modification of a methodology developed in our lab, between (S)-3-(dibenzylamino)butan-2-one 16 (derived from $L$-alanine) and tetradecanal 17. ${ }^{10}$ Interest in this series of compounds is evident by recent publications describing the synthesis of 1-deoxy-5-hydroxy sphingoid bases. ${ }^{11}$

\section{Results and Discussion}

The synthesis of the enigmols drew from the chiral pool, starting from $L$-alanine. Conversion into $(S)$-3-( $N, N$-dibenzyl)-alanine 14 was accomplished following literature procedures. ${ }^{12}$ Further manipulation of $\mathbf{1 4}$ to obtain the methyl ketone (S)-3-(dibenzylamino)butan-2-one 16 was achieved in two steps via the intermediate Weinreb amide in nearly quantitative yield, a significant improvement over direct conversion of the carboxylic acid. ${ }^{10 \mathrm{~b}}$

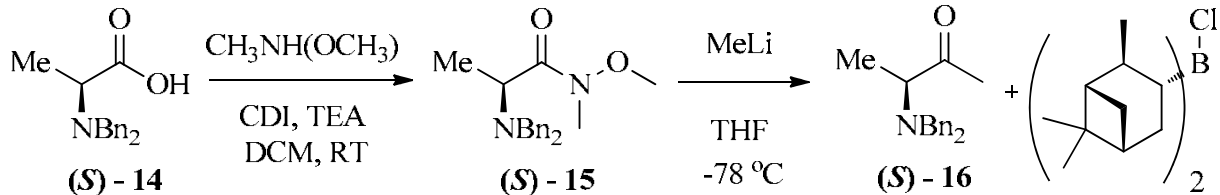

(S) -14

$-78^{\circ} \mathrm{C}$

$(-)-D I P-C l$

$\left(\mathrm{CH}_{3}\right)_{2} \mathrm{NC}_{2} \mathrm{H}_{5}, \mathrm{C}_{13} \mathrm{H}_{27} \mathrm{CHO}(17), \mathrm{THF},-78^{\circ} \mathrm{C}$

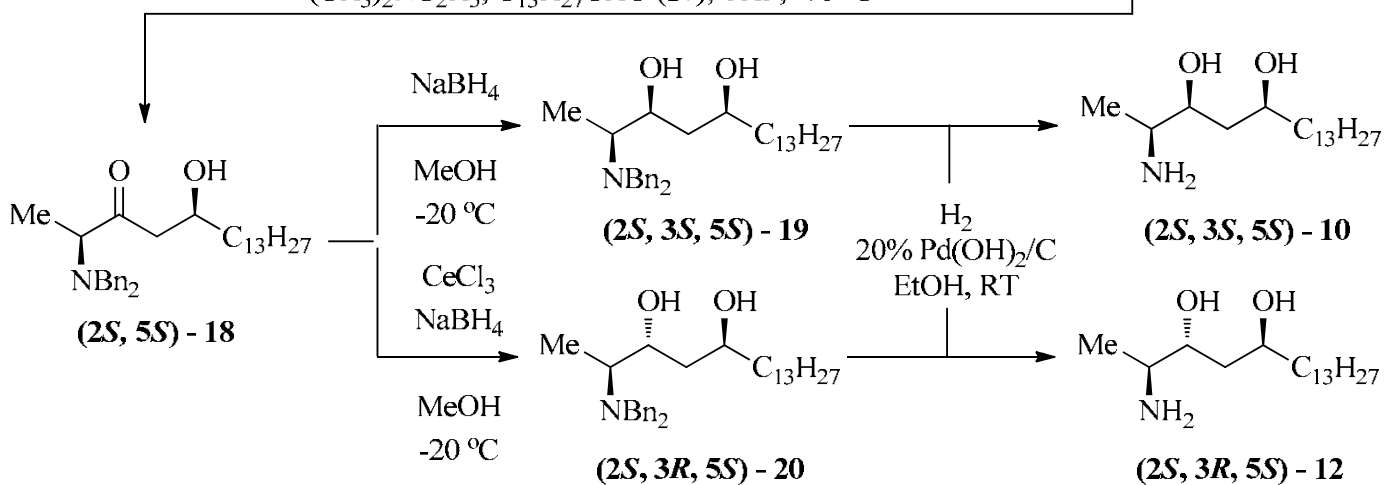

Scheme 2 
The aldol reaction of ketone 16 with tetradecanal 17 in the presence of (-)-diisopinocampheyl chloroborane ((-)-DIP-Cl) provided the corresponding (2S,5S)-keto derivative 18 exclusively. The extremely high diastereoselectivity (the $5 R$ product is not observed) of this aldol reaction is driven by the bulky $\mathrm{N}, \mathrm{N}$-dibenzyl substituent at C-2, a somewhat counterintuitive finding when using a chiral boron reagent. However, the same stereochemistry (5S) was observed independent of boron-ligand chirality. Reduction of ketone 18 with sodium borohydride proceeded smoothly to give $(2 S, 3 S, 5 S)$-aminodiol 19 without the observed formation of other products. To gain access to the inverse reduction product, Luche conditions were used, producing a 4:1 mixture of the anti 20 to syn 19 1,3-diol, which could be easily separated by flash chromatography. The enigmols 10 and 12 were then obtained from 19 and 20 following standard hydrogenolysis conditions with Pearlman's catalyst under 1 atmosphere of hydrogen.

In the early stages of development, the aldol chemistry between methyl ketone $\mathbf{1 6}$ and tetradecanal $17^{10 \mathrm{~b}}$ proved to be quite versatile for small-scale synthesis. However, when we attempted to utilize this approach on a gram scale, we observed partial- to total- loss of optical activity. The degree to which optical activity was reduced was substrate- and batch- dependent. After careful investigation it became apparent that the methyl ketone $\mathbf{1 6}$ and the 3-ketoderivative $\mathbf{1 8}$ are prone to racemization at C-2 under chromatographic conditions (on silica or neutral alumina). This conclusion was reinforced by the observation that initial fractions of methyl ketone $\mathbf{1 6}$ on silica gel produced a clear oil that had a greater specific rotation than later fractions, which had no optical rotation and became solid after drying. The epimerization of compound 18 occurred more slowly on silica than 16, and this process could be further retarded by neutralizing the silica with $1 \%$ triethylamine. To circumvent this problem, we developed a synthetic route to the methyl ketone 16 through the Weinreb amide 15, which obviated the need for purification and therefore racemization, before using $\mathbf{1 6}$ in the aldol reaction. Also, reduction of 18 was performed immediately after simple work-up, also avoiding racemization. The methyl ketone 16 can be stored at $-20{ }^{\circ} \mathrm{C}$ without racemization for several months. Chiral chromatography was used to verify that enantiopure methyl ketone 16 yielded only one enantiomer of $N, N$-dibenzyl-enigmol 19 after two consecutive steps without isolation of the intermediate compound 18 ( $>99.8 \%$ ee, HPLC).

Access to the remaining two $5 R$ - diastereomers was accomplished by performing a Mitsunobu inversion at that center. First, the free base $\mathbf{1 0}$ was regioselectively converted to oxazolidinone 21 with carbonyldiimidazole, tying up the C-2 and C-3 functionality. Next, the hydroxyl group at C-5 was inverted using standard conditions. Finally, microwave irradiation with lithium hydroxide at $120{ }^{\circ} \mathrm{C}$ for 1.5 hours gave the corresponding $(2 S, 3 S, 5 R)$-amino-diol 11. ${ }^{13}$ Similar reaction conditions were used to convert 12 into 13.

To confirm the absolute stereochemistry of the enigmol diastereomers, two methods were utilized. First, the oxazolidinone intermediates 21, 22, 25, and $26^{14}$ were converted into their corresponding C-5 Mosher esters and analyzed by NMR spectroscopy ${ }^{15}$ to confirm stereochemistry before $(S)$ and after $(R)$ Mitsonobu inversion. ${ }^{16}$ Next, the relative stereochemistry of the C-3/C-5 1,3-diols was confirmed using Rychnovsky's acetonide methodology with ${ }^{13} \mathrm{C}$ - 
NMR analysis. ${ }^{17}$ The syn- $(2 S, 3 S, 5 S)$ - acetonide showed resonances at 98.4, 30.6, and $19.7 \mathrm{ppm}$, and the anti- $(2 S, 3 R, 5 S)$-acetonide showed resonances at 100.3, 24.9, and $24.8 \mathrm{ppm}$. Finally, the $(S)$ - stereochemistry at C-2 was derived from the starting material $L$-alanine, and chiral HPLC was used to verify retention of stereochemistry at this center.
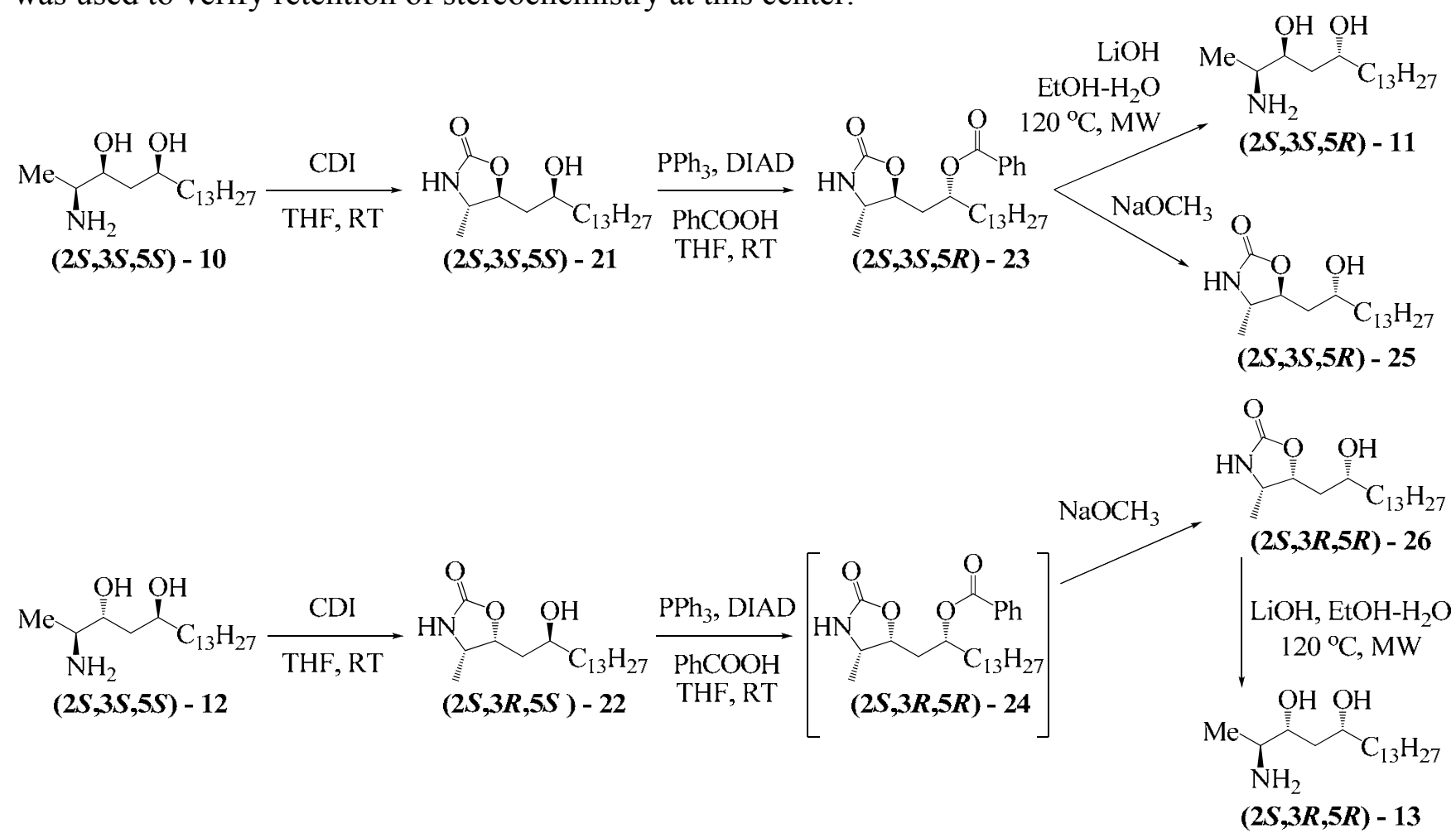

\section{Scheme 3}

\section{Conclusions}

Using the synthetic methodology described above, we have successfully prepared all four $2 S$ enigmol diastereomers. Although others have attempted to synthesize the enigmol amino-diol headgroup via a boron-mediated aldol reaction, ${ }^{11 \mathrm{~d}}$ this is the first example of a high yielding, completely diastereoselective application. In addition, we have successfully prepared $(2 S, 3 S, 5 S)$ and $(2 S, 3 R, 5 S)$-enigmols in gram quantities for biological evaluation, proving the scalability and reproducibility of our procedure.

\section{Experimental Section}

General. All reactions were run under inert atmosphere unless otherwise stated. All chemicals used were purchased from Sigma-Aldrich Chemical Co. and used without further purification, unless otherwise stated. All solvents termed "dry" were dried via a Glass Contour solvent 
purification system (SG Water, USA LLC). All melting points were obtained on a $200 \mathrm{~W}$ MelTemp apparatus and are uncorrected. ${ }^{1} \mathrm{H}$ NMR spectra were obtained on a $400 \mathrm{MHz}$ Varian Spectrometer, referenced to residual solvent or to TMS. ${ }^{13} \mathrm{C}$ NMR spectra were taken on a 100 $\mathrm{MHz}$ Varian Spectrometer referenced to the solvent carbon signal. Elemental analyses were performed by Atlantic Microlab, Inc (Norcross, GA). Infrared absorption spectra were obtained on a Thermo Scientific Nicolet 370 FT-IR spectrophotometer via the Smart Orbit Attenuated Total Reflectance accessory. High-resolution mass spectrometry was performed by the Emory University Mass Spectrometry Center (Dr. Fred Strobel). Optical rotation was measured on a Perkin Elmer 341 Polarimeter. Merck Silica Gel 60 TLC plates were used to monitor the reactions. Chiral HPLC was performed on a Varian ProStar using a Chiral Technologies Inc ChiralPak ${ }^{\circledR}$ AD-H $(0.46 \mathrm{~cm} \times 25 \mathrm{~cm})$ column, $1 \mathrm{~mL} / \mathrm{min}$ with isocratic conditions of 90:10 hexanes to isopropanol. TLC plates were visualized with: UV, $4 \%$ aq. $\mathrm{H}_{2} \mathrm{SO}_{4}$, Ninhydrin, or $\mathrm{KMnO}_{4}$. Flash column chromatography was done with a Teledyne ISCO CombiFlash Companion automated flash column system unless otherwise specified. Microwave reactions were performed in a Biotage Initiator microwave synthesizer.

(2S)-2-Dibenzylamino-propionic acid benzyl ester. Prepared as reported in the literature ${ }^{12}$ in $68 \%$ yield. $[\alpha]_{\mathrm{D}}{ }^{24}-97.6^{\circ}$ (c 1.1, ethyl acetate); ${ }^{1} \mathrm{H}$ NMR (400 MHz, $\left.\mathrm{CDCl}_{3}\right) \delta 7.45-7.25(\mathrm{~m}, 15$ H), $5.28(\mathrm{~d}, J=12.5 \mathrm{~Hz}, 1 \mathrm{H}), 5.20(\mathrm{~d}, J=12.5 \mathrm{~Hz}, 1 \mathrm{H}), 3.89(\mathrm{~d}, J=14.1 \mathrm{~Hz}, 2 \mathrm{H}), 3.69(\mathrm{~d}, J=$ $14.1 \mathrm{~Hz}, 2 \mathrm{H}), 3.62(\mathrm{q}, J=7.0 \mathrm{~Hz}, 1 \mathrm{H}), 1.40(\mathrm{~d}, J=7.0 \mathrm{~Hz}, 3 \mathrm{H}) ;{ }^{13} \mathrm{C}$ NMR $\left(100 \mathrm{MHz}, \mathrm{CDCl}_{3}\right)$ $\delta$ 173.7, 140.0 (2 C), 136.2, 128.7 (6 C), 128.4 (6 C), 127.0 (3 C), 66.2, 56.3, 54.5, 15.1. Lit. $[\alpha]_{\mathrm{D}}^{20}-91.8^{\circ}(\mathrm{c} 1$, ethyl acetate $) .{ }^{18}$

(2S)-2-Dibenzylamino-propionic acid (14). Prepared by the literature procedure ${ }^{12}$ in $97 \%$ yield. $[\alpha]_{\mathrm{D}}{ }^{24}-50^{\circ}(\mathrm{c} 5.3, \mathrm{MeOH}) ;{ }^{1} \mathrm{H}$ NMR $\left(400 \mathrm{MHz}, \mathrm{CDCl}_{3}\right) \delta 7.35-7.25(\mathrm{~m}, 10 \mathrm{H}), 3.92(\mathrm{~d}, J=13.4$ $\mathrm{Hz}, 2 \mathrm{H}), 3.71(\mathrm{~d}, J=13.4 \mathrm{~Hz}, 2 \mathrm{H}), 3.58(\mathrm{q}, J=7.0 \mathrm{~Hz}, 1 \mathrm{H}), 1.40(\mathrm{~d}, J=7.0 \mathrm{~Hz}, 3 \mathrm{H}) ;{ }^{13} \mathrm{C}$ NMR $\left(100 \mathrm{MHz}, \mathrm{CDCl}_{3}\right) \delta 174.9,136.6,129.3,128.9,128.3,57.9,54.6,11.7 ;$ HRMS (ESI) $\mathrm{m} / \mathrm{z}$ 270.14912 (theoretical for $\mathrm{C}_{17} \mathrm{H}_{19} \mathrm{NO}_{2}+\mathrm{H}$ : 270.14886). Lit. $[\alpha]_{\mathrm{D}}{ }^{20}-44.9^{\circ}\left(c\right.$ 2.0, MeOH). ${ }^{19}$

(2S)-2-Dibenzylamino- $N$-methoxy- $N$-methylpropanamide (15). Synthesized by the method reported in the literature. ${ }^{20} 1,1^{\prime}$-Carbonyldiimidazole $(12.33 \mathrm{~g}, 76.04 \mathrm{mmol})$ was added at $0{ }^{\circ} \mathrm{C}$ to a stirring solution of (2S)-2-dibenzylamino-propionic acid 14 (10.25 g, $38.06 \mathrm{mmol})$ in dry dichloromethane (DCM, $130 \mathrm{~mL}$ ). After 50 minutes, a heterogeneous mixture of $\mathrm{N}$, O-dimethylhydroxylamine hydrochloride $(7.42 \mathrm{~g}, 76.1 \mathrm{mmol})$ and triethylamine $\left(\mathrm{Et}_{3} \mathrm{~N}, 10.6 \mathrm{~mL}\right.$, $76.1 \mathrm{mmol})$ in dry DCM $(75 \mathrm{~mL})$ was added, and the mixture was stirred at $0{ }^{\circ} \mathrm{C}$ for 1 hour, and then allowed to warm to room temperature overnight. The reaction mixture was taken into diethyl ether $\left(\mathrm{Et}_{2} \mathrm{O}\right)$, washed with $1 \mathrm{M} \mathrm{HCl}$, saturated sodium bicarbonate, brine, dried over magnesium sulfate, and concentrated in vacuo. The crude material was purified by flash chromatography $\left(\mathrm{SiO}_{2}\right.$, hexane: ethyl acetate) to yield a clear oil (12.7 g), which was recrystallized from hexane to give the desired compound as a colorless crystalline product $(11.70 \mathrm{~g}, 98 \%) . \mathrm{R}_{\mathrm{f}}=0.48\left(2: 1\right.$ hexane: ethyl acetate); $\mathrm{mp} 59-60{ }^{\circ} \mathrm{C}$; IR $\left(v_{\max }, \mathrm{cm}^{-1}\right): 3067,3024$, 2980, 2942, 2862, 2841, 2820, 1650, 1451, 1364, 1161, 1141, 1073, 993, 748, 731, 697, 645, 
616; $[\alpha]_{\mathrm{D}}{ }^{24}=+19.8^{\circ}\left(c 2.1, \mathrm{CHCl}_{3}\right) ;{ }^{1} \mathrm{H}$ NMR (400 MHz, $\left.\mathrm{CDCl}_{3}\right) \delta 7.38(\mathrm{~d}, J=7.3 \mathrm{~Hz}, 4 \mathrm{H})$, $7.31(\mathrm{t}, J=7.4 \mathrm{~Hz}, 4 \mathrm{H}), 7.22(\mathrm{~d}, J=7.3 \mathrm{~Hz}, 2 \mathrm{H}), 4.00-3.78(\mathrm{~m}, 5 \mathrm{H}), 3.3-3.1(\mathrm{~m}, 6 \mathrm{H}), 1.35$ $(\mathrm{d}, J=7.0 \mathrm{~Hz}, 3 \mathrm{H}) ;{ }^{13} \mathrm{C}$ NMR $\left(100 \mathrm{MHz}, \mathrm{CDCl}_{3}\right) \delta 175.5,140.5,128.7,128.1,126.8,60.8$, 54.5, 52.2, 31.8, 14.0; HRMS (ESI) $\mathrm{m} / \mathrm{z} 313.19114$ (theoretical for $\mathrm{C}_{19} \mathrm{H}_{24} \mathrm{~N}_{2} \mathrm{O}_{2}+\mathrm{H}$ : 313.19105); Anal. Calcd. for $\mathrm{C}_{19} \mathrm{H}_{24} \mathrm{~N}_{2} \mathrm{O}_{2}$ : C, 73.05; H, 7.74; N, 8.97. Found: C, 73.04; H, 7.66; N, 8.99. Lit. $\mathrm{mp}=58^{\circ} \mathrm{C} ;[\alpha]_{\mathrm{D}}{ }^{20}=+19.5^{\circ}(\mathrm{c} 1.0, \mathrm{DCM}) .^{21}$

(S)-3-(Dibenzylamino)butan-2-one (16). Methyllithium (66.8 $\mathrm{mL}$ of $1.6 \mathrm{M}$ in $\left.\mathrm{Et}_{2} \mathrm{O}, 107 \mathrm{mmol}\right)$ was slowly added to a stirred solution of $(S)$-2-dibenzylamino-N-methoxy-N-methylpropanamide 15 (11.6 g, $37.3 \mathrm{mmol})$ in dry tetrahydrofuran (THF, $300 \mathrm{~mL}$ ) at $-78{ }^{\circ} \mathrm{C}$ over a period of 45 minutes. The resulting solution was stirred for another 30 minutes. The reaction was quenched with saturated ammonium chloride and extracted with $\mathrm{Et}_{2} \mathrm{O}(3 \mathrm{~L})$. The ether solution was then washed with water, brine, dried over magnesium sulfate, and concentrated in vacuo to yield the methyl ketone $\mathbf{1 6}$ as a pale yellow oil (9.89 g, 99\%), which was used in the next step without additional purification. $\mathrm{R}_{\mathrm{f}}=0.42$ (9:1 hexanes: ethyl acetate); $\mathrm{mp}=43-44{ }^{\circ} \mathrm{C}$; IR ( $v_{\max }$, $\left.\mathrm{cm}^{-1}\right)$ : 3024, 2872, 2841, 2810, 1709, 1493, 1454, 1381, 1348, 1187, 1145, 1071, 1029, 968, 744, 729, 699, 594, 499, 460; $[\alpha]_{\mathrm{D}}{ }^{24}-55.4^{\circ}\left(\mathrm{c} 3.2, \mathrm{CHCl}_{3}\right) ;{ }^{1} \mathrm{H} \mathrm{NMR}\left(400 \mathrm{MHz}, \mathrm{CDCl}_{3}\right) \delta 7.39$ (d, J= $7.2 \mathrm{~Hz}, 4 \mathrm{H}), 7.34$ (t, $J=8.0 \mathrm{~Hz}, 4 \mathrm{H}), 7.26(\mathrm{t}, J=6.8 \mathrm{~Hz}, 2 \mathrm{H}), 3.70(\mathrm{~d}, J=13.6 \mathrm{~Hz}, 2 \mathrm{H}), 3.45$ $(\mathrm{d}, J=13.6 \mathrm{~Hz}, 2 \mathrm{H}), 3.36(\mathrm{q}, J=6.8 \mathrm{~Hz}, 1 \mathrm{H}), 2.23(\mathrm{~s}, 3 \mathrm{H}), 1.16(\mathrm{~d}, J=6.8 \mathrm{~Hz}, 3 \mathrm{H}) ;{ }^{13} \mathrm{C} \mathrm{NMR}$ $\left(100 \mathrm{MHz}, \mathrm{CDCl}_{3}\right) \delta 211.2,139.5,128.9,128.6,127.4,63.1,54.8$ (2 C), 27.9, 7.2; HRMS (ESI) m/z 268.16985 (theoretical for $\mathrm{C}_{18} \mathrm{H}_{21} \mathrm{NO}+\mathrm{H}: 268.16959$ ); Anal. Calcd. for $\mathrm{C}_{18} \mathrm{H}_{21} \mathrm{NO}$ : C, 80.86; H, 7.92; N, 5.24. Found: C, 80.76; H, 7.93; N, 5.30\%.

Tetradecanal (17). Pyridinium chlorochromate $(37.7 \mathrm{~g}, 175 \mathrm{mmol})$ and Celite $(37.7 \mathrm{~g})$ were mixed in DCM (200 mL). To this mixture was added a solution of tetradecanol (25.0 g, $117 \mathrm{mmol})$ in DCM (165 mL) over a 90 minute period via addition funnel. Reaction mixture was stirred for 1 hour at which point all the starting material had been completely consumed. The mixture was passed through a silica plug and the product was eluted with DCM to give a clear colorless oil $(22.6 \mathrm{~g}, 91 \%)$. Tetradecanal was stored at $-20{ }^{\circ} \mathrm{C}$. Before use, tetradecanal trimers were cracked by short path distillation under vacuum $\left(0.2 \mathrm{~mm} \mathrm{Hg}\right.$ at $110-130{ }^{\circ} \mathrm{C}$, matching reported literature values). ${ }^{22}$

(2S,5S)-2-(Dibenzylamino)-5-hydroxyoctadecan-3-one (18). To a stirred solution of (-) DIP-Cl (50-65 wt.\% in hexanes, $10.4 \mathrm{~mL}, 14.0 \mathrm{mmol}$ ) in dry THF (45 mL), was added dimethyl ethylamine $(4.86 \mathrm{~mL}, 44.9 \mathrm{mmol})$ dropwise at room temperature. The reaction mixture was then cooled to $-30{ }^{\circ} \mathrm{C}$, and a solution of $(S)$-3-(dibenzylamino)butan-2-one 16 (3.00 g, $\left.11.2 \mathrm{mmol}\right)$ in dry THF $(21 \mathrm{~mL})$ was added dropwise over a 15 minute period at $-30{ }^{\circ} \mathrm{C}$. The resulting mixture was stirred for an additional 1.5 hours at $-30{ }^{\circ} \mathrm{C}$ and then cooled to $-78{ }^{\circ} \mathrm{C}$. A solution of freshly distilled tetradecanal $17(4.77 \mathrm{~g}, 22.4 \mathrm{mmol})$ in dry THF $(31 \mathrm{~mL})$ was then added dropwise over the next 2 hours. The mixture was kept at $-78{ }^{\circ} \mathrm{C}$ overnight, at which point no starting material remained. The reaction mixture was quenched by the addition of a phosphate buffer $(45 \mathrm{~mL}, \mathrm{pH}$ $=7$ ) over 3 minutes at $-20{ }^{\circ} \mathrm{C}$, and stirring was continued over the next hour while the reaction was allowed to warm to room temperature. The mixture was then cooled to $-20{ }^{\circ} \mathrm{C}$, and hydrogen 
peroxide ( $30 \%$ solution in water, $0.9 \mathrm{~mL}, 9 \mathrm{mmol}$ ) was added dropwise to the stirred mixture. After stirring for an additional hour, the reaction mixture was diluted with $\mathrm{Et}_{2} \mathrm{O}(1.5 \mathrm{~L})$, washed with brine, dried over magnesium sulfate, filtered, and concentrated in vacuo (theoretical yield $=$ $5.38 \mathrm{~g}$, crude mass $=14.3 \mathrm{~g}$ ). This compound was immediately used in next step without further purification or analysis. $\mathrm{R}_{\mathrm{f}}=0.59$ (4:1 hexanes: ethyl acetate); $[\alpha]_{\mathrm{D}}{ }^{24}=-36.9^{\circ}\left(c 2.7, \mathrm{CHCl}_{3}\right)$, $55.9^{\circ}$ (c 2.7, MeOH); ${ }^{23} \mathrm{HRMS}$ (ESI) $\mathrm{m} / \mathrm{z} 480.38360$ (theoretical for $\mathrm{C}_{32} \mathrm{H}_{49} \mathrm{NO}_{2}+\mathrm{H}: 480.38492$ ). (2S,3S,5S)-2-(Dibenzylamino)octadecane-3,5-diol (19). To a stirred solution of crude 3-ketoderivative 18 (theoretically $5.38 \mathrm{~g}, 11.2 \mathrm{mmol}$ ) in methanol $(70 \mathrm{ml})$ at $-20{ }^{\circ} \mathrm{C}$ was added granulated sodium borohydride $(770 \mathrm{mg}, 18.8 \mathrm{mmol}$ ) in 3 portions, and the resulting mixture was stirred for 1 hour at $-20{ }^{\circ} \mathrm{C}$, then allowed to warm to $0{ }^{\circ} \mathrm{C}$. The reaction mixture was then quenched by the dropwise addition of glacial acetic acid $(4 \mathrm{ml}, 59 \mathrm{mmol})$, concentrated under vacuum, and the resulting residue was diluted with $\mathrm{Et}_{2} \mathrm{O}$, washed with saturated sodium bicarbonate, brine, dried over magnesium sulfate and concentrated under vacuum to give the crude product as an oil $(11.0 \mathrm{~g})$. The crude reaction mixture was subjected to sublimation at 0.2 $\mathrm{mm} \mathrm{Hg}$ at $50{ }^{\circ} \mathrm{C}$ for 24 hours to remove pinene byproducts derived from DIP-Cl, and the remaining oil $(8.4 \mathrm{~g})$ was purified by flash chromatography $\left(\mathrm{SiO}_{2}\right.$, hexanes: ethyl acetate, both containing $2 \%$ triethylamine) to yield dibenzylaminodiol 19 as a waxy solid $(4.62 \mathrm{~g}, 86 \%)$. $\mathrm{R}_{\mathrm{f}}=$ 0.54 (4:1 hexanes: ethyl acetate); IR $\left(v_{\max }, \mathrm{cm}^{-1}\right): 3400,3030,2921,2851,1453,1378,1301$, $1142,1301,1097,1058,1028,841,745,731,697 ;[\alpha]_{\mathrm{D}}{ }^{24}=+32.4^{\circ}\left(c 1.5, \mathrm{CHCl}_{3}\right) ;{ }^{1} \mathrm{H}$ NMR $(400$ $\left.\mathrm{MHz}, \mathrm{CDCl}_{3}\right) \delta 7.35-7.21(\mathrm{~m}, 10 \mathrm{H}), 4.73(\mathrm{bs}, 1 \mathrm{H}), 4.01(\mathrm{bs}, 1 \mathrm{H}), 3.80(\mathrm{~m}, 1 \mathrm{H}), 3.79(\mathrm{~d}, J=$ $13.3 \mathrm{~Hz}, 2 \mathrm{H}), 3.63(\mathrm{dt}, J=7.9,2.5 \mathrm{~Hz}, 1 \mathrm{H}), 3.28(\mathrm{~d}, J=13.0 \mathrm{~Hz}, 2 \mathrm{H}), 2.53(\mathrm{~m}, 1 \mathrm{H}), 1.81(\mathrm{~d}, J$ $=14.0 \mathrm{~Hz}, 1 \mathrm{H}), 1.68(\mathrm{~m}, 1 \mathrm{H}), 1.5-1.2(\mathrm{~m}, 24 \mathrm{H}), 1.2-1.0(\mathrm{~m}, 2 \mathrm{H}), 0.99(\mathrm{~d}, J=6.7 \mathrm{~Hz}, 3 \mathrm{H})$, $0.90(\mathrm{t}, J=7.0 \mathrm{~Hz}, 3 \mathrm{H}) ;{ }^{13} \mathrm{C}$ NMR $\left(100 \mathrm{MHz}, \mathrm{CDCl}_{3}\right) \delta 140.1,129.1,128.5,127.2,71.3,70.0$, 57.1, 54.8, 39.3, 37.8, 32.1, 29.9 (2 C), 29.6 (6 C), 26.0, 22.9, 14.3, 8.7; HRMS (ESI) m/z 482.39942 (theoretical for $\mathrm{C}_{32} \mathrm{H}_{51} \mathrm{NO}_{2}+\mathrm{H}: 482.39926$ ); Anal. Calcd. for $\mathrm{C}_{32} \mathrm{H}_{51} \mathrm{NO}_{2}$ : C, 79.78; $\mathrm{H}$, 10.67; N, 2.91. Found: C 79.70; H 10.70; N 2.91\%.

(2S,3R,5S)-2-(Dibenzylamino)octadecane-3,5-diol (20). To a stirred solution of crude 3-keto derivative 18 (theoretically $5.38 \mathrm{~g}, 11.2 \mathrm{mmol})$ in $\mathrm{MeOH}(225 \mathrm{~mL})$ at $-20{ }^{\circ} \mathrm{C}$ was added cerium (III) chloride heptahydrate $(8.46 \mathrm{~g}, 22.7 \mathrm{mmol})$. The mixture was stirred for 20 minutes at $-20^{\circ} \mathrm{C}$, followed by addition of granulated sodium borohydride $(850 \mathrm{mg}, 22.5 \mathrm{mmol}$ ) in 9 portions of $\sim 100 \mathrm{mg}$ each with continued stirring until no starting material remained. The resulting mixture was quenched by the dropwise addition of glacial acetic acid $(\sim 2 \mathrm{~mL})$, and the resulting mixture was concentrated in vacuo, diluted with $\mathrm{Et}_{2} \mathrm{O}$, and neutralized with saturated sodium bicarbonate. The solids were then filtered off, and the organic layer was isolated and washed with water, brine, dried over magnesium sulfate, and concentrated under vacuum to give the crude product as an oil (12.4 g). After this material was subjected to sublimation at $0.2 \mathrm{~mm} \mathrm{Hg}$ at $50{ }^{\circ} \mathrm{C}$ for 24 hours to remove pinene byproducts derived from DIP-Cl, the remaining oil $(7.5 \mathrm{~g})$ was purified by flash chromatography $\left(\mathrm{SiO}_{2}\right.$, hexanes: ethyl acetate, both containing $2 \%$ triethylamine) to yield $\mathbf{2 0}$ as a waxy colorless solid $(3.60 \mathrm{~g}, 67 \%)$. Compound 19 was also isolated as a waxy colorless solid (761 mg, 11\%). $R_{\mathrm{f}}=0.27$ (4:1 hexanes: ethyl acetate); IR $\left(v_{\max }, \mathrm{cm}^{-1}\right): 3317,2918,2849,1493$, 
1469, 1452, 1367, 1110, 1064, 1027, 996, 728, 696; $[\alpha]_{\mathrm{D}}{ }^{24}=+20.5{ }^{\circ}\left(c\right.$ 2.2, $\left.\mathrm{CHCl}_{3}\right)$; ${ }^{1} \mathrm{H}$ NMR $\left(400 \mathrm{MHz}, \mathrm{CDCl}_{3}\right) \delta 7.35-7.21(\mathrm{~m}, 10 \mathrm{H}), 3.89(\mathrm{dt}, J=7.9,2.5 \mathrm{~Hz}, 1 \mathrm{H}), 3.74(\mathrm{~d}, J=13.3 \mathrm{~Hz}, 2$ H), 3.61 (m, 1 H), 3.41 (d, J=14.6 Hz, $2 \mathrm{H}), 3.10$ (bs, $1 \mathrm{H}), 2.73$ (m, $1 \mathrm{H}), 2.32$ (bs, $1 \mathrm{H}), 1.77$ $(\mathrm{m}, 1 \mathrm{H}), 1.63(\mathrm{~m}, 1 \mathrm{H}), 1.5-1.2(\mathrm{~m}, 23 \mathrm{H}), 1.13(\mathrm{~d}, J=6.7 \mathrm{~Hz}, 3 \mathrm{H}), 0.87(\mathrm{t}, J=7.0 \mathrm{~Hz}, 3 \mathrm{H})$; ${ }^{13} \mathrm{C} \mathrm{NMR}\left(100 \mathrm{MHz}, \mathrm{CDCl}_{3}\right) \delta 140.1,129.1,128.5,127.2,71.3,70.0,57.1,54.8(2 \mathrm{C}), 39.3$, 37.8, 32.1, 29.9 (2 C), 29.6 (6 C), 26.0, 22.9, 14.3, 8.7; HRMS (ESI) m/z 482.39942 (theoretical for $\mathrm{C}_{32} \mathrm{H}_{51} \mathrm{NO}_{2}+\mathrm{H}$ : 482.39926); Anal. Calcd. for $\mathrm{C}_{32} \mathrm{H}_{51} \mathrm{NO}_{2}$ : C, 79.78; H, 10.67; N, 2.91. Found: C 79.97; H 11.16; N 2.69\%.

(2S,3S,5S)-2-Aminooctadecane-3,5-diol (10). $N, N$-Dibenzyl-S,S,S-enigmol 19 (299 mg, $620 \mu \mathrm{mol}$ ) and Pearlman's catalyst (wet, $160 \mathrm{mg}, 0.23 \mathrm{mmol}$ ) were taken up in ethanol (190 proof, $250 \mathrm{~mL}$ ). The heterogeneous solution was then evacuated and purged with hydrogen gas (1 atm.). The resulting mixture was stirred vigorously for 3.5 hours at which point no starting material remained, and the mixture was filtered over Celite. The solvent was then evaporated under reduced pressure, and the white powdery solid obtained was washed with hexanes to remove any impurities $(163 \mathrm{mg}, 87 \%) . \mathrm{R}_{\mathrm{f}}=0.40\left(45: 10: 1 \mathrm{CHCl}_{3}: \mathrm{MeOH}\right.$ :ammonium hydroxide (aq. 25\%)), and 0.49 (20:5:2:1 $\mathrm{CHCl}_{3}: \mathrm{MeOH}$ :acetic acid:water); $\mathrm{mp}=64-65^{\circ} \mathrm{C}$; IR $\left(v_{\max }, \mathrm{cm}^{-1}\right): 3402$, 3328, 2917, 2847, 1596, 1463, 1325, 1170, 1142, 1120, 1075, 1020, 984, 919, 845, 818, 721, $607 ;[\alpha]_{\mathrm{D}}{ }^{24}=+3.3^{\circ}\left(c 1.6, \mathrm{CHCl}_{3}\right),-10.6^{\circ}(c$ 1.6, MeOH$) ;{ }^{1} \mathrm{H}$ NMR $\left(400 \mathrm{MHz}, \mathrm{CD}_{3} \mathrm{OD}\right) \delta 3.86$ $(\mathrm{m}, 1 \mathrm{H}), 3.46(\mathrm{~m}, 1 \mathrm{H}), 2.75$ (quintet, $J=6.1 \mathrm{~Hz}, 1 \mathrm{H}), 1.64(\mathrm{dt}, J=14.3,2.4 \mathrm{~Hz}, 1 \mathrm{H}), 1.55$ $1.35(\mathrm{~m}, 5 \mathrm{H}), 1.35-1.20(\mathrm{~m}, 22 \mathrm{H}), 1.08(\mathrm{~d}, J=6.7 \mathrm{~Hz}, 3 \mathrm{H}), 0.88(\mathrm{t}, J=7.0 \mathrm{~Hz}, 3 \mathrm{H}) ;{ }^{13} \mathrm{C}$ NMR (100 MHz, $\left.\mathrm{CD}_{3} \mathrm{OD}\right) \delta 72.2$ (2 C), 51.8, 40.5, 38.2, 32.1, 29.9 (7 C), 29.7, 25.7, 22.9, 21.1, 14.3; HRMS (ESI) m/z 302.30550 (theoretical for $\mathrm{C}_{18} \mathrm{H}_{39} \mathrm{NO}_{2}+\mathrm{H}: 302.30590$ ); Anal. Calcd. for $\mathrm{C}_{18} \mathrm{H}_{39} \mathrm{NO}_{2}$ : C, 71.70; H, 13.01; N, 4.65. Found: C 71.76; H 13.26; N 4.64\%.

(2S,3R,5S)-2-Aminooctadecane-3,5-diol (12). $\quad N, N$-Dibenzyl-S,R,S-enigmol $20 \quad(2.69$ g, $5.58 \mathrm{mmol}$ ) and Pearlman's catalyst (wet, $1.44 \mathrm{~g}, 2.05 \mathrm{mmol}$ ) were taken up in ethanol (190 proof, $250 \mathrm{~mL}$ ). The heterogeneous solution was then evacuated and purged with hydrogen gas (1 atm.). The resulting mixture was stirred vigorously for 3.5 hours at which point no starting material remained, and the mixture was filtered over Celite. The solvent was then evaporated in vacuo, and the crude product was purified by flash chromatography $\left(\mathrm{SiO}_{2}, 84: 15: 1 \mathrm{DCM}\right.$ : $\mathrm{MeOH}$ : ammonium hydroxide (aq. $25 \%)$ ) to yield 12 as a white powder $(1.57 \mathrm{~g}, 93 \%)$. $\mathrm{R}_{\mathrm{f}}=0.20$ (84:15:1 DCM: MeOH: ammonium hydroxide (aq. 25\%)), and 0.46 (20:5:2:1 $\mathrm{CHCl}_{3}: \mathrm{MeOH}$ :acetic acid: water); $\mathrm{mp}=86-92{ }^{\circ} \mathrm{C}$; IR $\left(v_{\max }, \mathrm{cm}^{-1}\right): 3331,2916,2849,1581$, $1555,1469,1403,1389,1302,1045,1021,718,674 ;[\alpha]_{\mathrm{D}}{ }^{24}=+17.7^{\circ}(c 0.85, \mathrm{MeOH}) ;{ }^{1} \mathrm{H} \mathrm{NMR}$

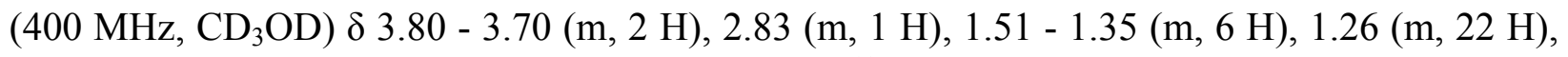
$1.05(\mathrm{~d}, J=6.7 \mathrm{~Hz}, 3 \mathrm{H}), 0.87(\mathrm{t}, J=7.0 \mathrm{~Hz}, 3 \mathrm{H}) ;{ }^{13} \mathrm{C} \mathrm{NMR}\left(100 \mathrm{MHz}, \mathrm{CD}_{3} \mathrm{OD}\right) \delta 72.9,69.4$, 52.9, 41.2, 39.5, 33.2, 31.0 (7 C), 30.7, 27.0, 23.9, 17.2, 14.6; HRMS (ESI) m/z 302.30551 (theoretical for $\mathrm{C}_{18} \mathrm{H}_{39} \mathrm{NO}_{2}+\mathrm{H}$ : 302.30590); Anal. Calcd. for $\mathrm{C}_{18} \mathrm{H}_{39} \mathrm{NO}_{2}+0.75 \cdot \mathrm{H}_{2} \mathrm{O}$ : C, 68.63; H, 12.96; N, 4.45. Found: C 68.74; H 12.50; N 4.28\%.

(4S,5S)-5-((S)-2-Hydroxypentadecyl)-4-methyloxazolidin-2-one (21). To a stirred solution of $(2 S, 3 S, 5 S)$-enigmol $10(167 \mathrm{mg}, 554 \mu \mathrm{mol})$ in dry THF $(15 \mathrm{~mL})$ was added a solution of 1,1'- 
carbonyldiimidazole $(121 \mathrm{mg}, 401 \mu \mathrm{mol})$ in dry THF $(2 \mathrm{~mL})$, dropwise, at $0{ }^{\circ} \mathrm{C}$. After addition was complete, the reaction was allowed to warm to ambient temperature over 3.5 hours. The reaction mixture was quenched by addition of $\mathrm{MeOH}$ and the solvents were evaporated under reduced pressure. The crude material was purified by flash chromatography $\left(\mathrm{SiO}_{2}\right.$, hexanes: ethyl acetate) to give a white solid (156 mg, 86\%). $\mathrm{R}_{\mathrm{f}}=0.48$ (9:1:1, $\mathrm{CHCl}_{3}: \mathrm{MeOH}$ :acetone); $\mathrm{mp}=87$ $-88{ }^{\circ} \mathrm{C}$; IR $\left(v_{\max }, \mathrm{cm}^{-1}\right): 3224,2918,2849,1720,1469,1428,1388,1330,1072,1030,960,719$; $[\alpha]_{\mathrm{D}}{ }^{24}=-31.8^{\circ}(\mathrm{c} 1.5, \mathrm{MeOH}) ;{ }^{1} \mathrm{H} \mathrm{NMR}\left(400 \mathrm{MHz}, \mathrm{CDCl}_{3}\right) \delta 4.31(\mathrm{~m}, 1 \mathrm{H}), 3.83(\mathrm{~m}, 1 \mathrm{H}), 3.68$ $(\mathrm{m}, 1 \mathrm{H}), 2.10(\mathrm{~m}, 1 \mathrm{H}), 1.89(\mathrm{~m}, 1 \mathrm{H}), 1.80(\mathrm{~m}, 1 \mathrm{H}), 1.55-1.40(\mathrm{~m}, 3 \mathrm{H}), 1.26(\mathrm{~m}, 23 \mathrm{H}), 0.89$ $(\mathrm{t}, J=7.0 \mathrm{~Hz}, 3 \mathrm{H}) ;{ }^{13} \mathrm{C} \mathrm{NMR}\left(100 \mathrm{MHz}, \mathrm{CDCl}_{3}\right) \delta 159.1,82.9,69.3,54.0,41.2,37.3,32.1,29.9$ (4 C), 29.8 (3 C), 29.6, 25.7, 22.9, 20.5, 14.3; HRMS (ESI) m/z 328.28480 (theoretical for $\mathrm{C}_{19} \mathrm{H}_{37} \mathrm{NO}_{3}+\mathrm{H}$ : 328.28519); Anal. Calcd. for $\mathrm{C}_{19} \mathrm{H}_{37} \mathrm{NO}_{3} \bullet 0.25 \mathrm{H}_{2} \mathrm{O}: \mathrm{C}, 68.73 ; \mathrm{H}, 11.38 ; \mathrm{N}, 4.22$. Found: C 68.95; H 11.41; N 4.21\%.

(R)-1-((4S,5S)-4-Methyl-2-oxazolidin-5-yl)pentadecan-2-yl benzoate (23). This compound was synthesized by the method reported in literature. ${ }^{24}$ To a solution of oxazolidinone 21 $(610 \mathrm{mg}, 1.86 \mathrm{mmol})$ in dry THF $(10 \mathrm{~mL})$ was added triphenyphosphine $(1.46 \mathrm{~g}, 5.55 \mathrm{mmol})$ and benzoic acid $(1.12 \mathrm{~g}, 9.16 \mathrm{mmol})$ at $0{ }^{\circ} \mathrm{C}$. The resultant mixture was allowed to stir at $0{ }^{\circ} \mathrm{C}$ for 15 minutes, to which diisopropyl azodicarboxylate $(1.90 \mathrm{~mL}, 9.16 \mathrm{mmol})$ was added. After 1 hour at $0{ }^{\circ} \mathrm{C}$, the mixture was then diluted with $\mathrm{Et}_{2} \mathrm{O}$, washed with the aqueous saturated sodium bicarbonate, brine, dried over magnesium sulfate, and concentrated in vacuo to give the crude product $(4.9 \mathrm{~g})$. The resulting material was taken into hexanes and filtered, then concentrated and purified by flash chromatography $\left(\mathrm{SiO}_{2}\right.$, hexanes: ethyl acetate) to yield 23 as an off-white powder $(736 \mathrm{mg}, 92 \%) . \mathrm{R}_{\mathrm{f}}=0.40\left(1: 1\right.$ hexanes: ethyl acetate); $\mathrm{mp}=61-62{ }^{\circ} \mathrm{C}$; IR $\left(v_{\max }, \mathrm{cm}^{-1}\right)$ : $3276,2919,2850,1731,1712,1273,1229,1109,1069,1023,707,673 ;[\alpha]^{24}=-42.4^{\circ}(c 1.1$, $\left.\mathrm{CHCl}_{3}\right),-45.4^{\circ}(\mathrm{c} 1.1, \mathrm{MeOH}) ;{ }^{1} \mathrm{H}$ NMR $\left(400 \mathrm{MHz}, \mathrm{CDCl}_{3}\right) \delta 8.04(\mathrm{~m}, 2 \mathrm{H}) ; 7.58(\mathrm{~m}, 1 \mathrm{H}) ; 7.46$ $(\mathrm{m}, 2 \mathrm{H}) ; 5.37(\mathrm{bs}, 1 \mathrm{H}), 5.30(\mathrm{~m}, 1 \mathrm{H}), 4.24(\mathrm{~m}, 1 \mathrm{H}), 3.62(\mathrm{~m}, 1 \mathrm{H}), 2.06(\mathrm{~m}, 2 \mathrm{H}), 1.75(\mathrm{~m}, 2$ $\mathrm{H}), 1.4-1.2(\mathrm{~m}, 25 \mathrm{H}), 0.88(\mathrm{t}, J=7.0 \mathrm{~Hz}, 3 \mathrm{H}) ;{ }^{13} \mathrm{C} \mathrm{NMR}\left(100 \mathrm{MHz}, \mathrm{CDCl}_{3}\right) \delta 166.2,159.2$, 133.2 , 130.4, 129.7, 128.6, 81.3, 72.1, 54.1, 39.3, 32.1, 29.8 (4 C), 29.7 (4 C), 29.5, 25.3, 22.9, 20.5, 14.3; HRMS (ESI) m/z 432.30999 (theoretical for $\mathrm{C}_{26} \mathrm{H}_{41} \mathrm{NO}_{4}+\mathrm{H}: 432.10830$ ).

(4S,5S)-5-((R)-2-Hydroxypentadecyl)-4-methyloxazolidin-2-one (25). To a solution of oxizolidinone-benzoate $23(112 \mathrm{mg}, 260 \mu \mathrm{mol})$ in $\mathrm{MeOH}(5 \mathrm{~mL})$ was added sodium methoxide ( $1 \mathrm{~mL}, 30 \%$ solution in $\mathrm{MeOH}$ ) and the resulting mixture was stirred for 3 hours at room temperature, neutralized with glacial acetic acid, and concentrated in vacuo. The resulting residue was dissolved in $\mathrm{Et}_{2} \mathrm{O}$, washed with saturated sodium bicarbonate, brine, dried over magnesium sulfate, and concentrated under vacuum. The remaining residue was washed with hexanes to yield 25 as a white powder (70 mg, 82\%). $\mathrm{R}_{\mathrm{f}}=0.48$ (9:1:1, $\mathrm{CHCl}_{3}: \mathrm{MeOH}$ :acetone); $\mathrm{mp}=112-114{ }^{\circ} \mathrm{C}$; IR $\left(v_{\max }, \mathrm{cm}^{-1}\right): 3298,3123,2921,2850,1717,1467,1407,1250,1068$, 1012, 912, 773, 728, 693, 647; $[\mathrm{a}]_{\mathrm{D}}{ }^{24}=-42.5^{\circ}\left(c 1.0, \mathrm{CHCl}_{3}\right)$ and $-50.2^{\circ}($ c 1.0, $\mathrm{MeOH}) ;{ }^{1} \mathrm{H}$ NMR $\left(400 \mathrm{MHz}, \mathrm{CDCl}_{3}\right) \delta 4.41(\mathrm{~m}, 1 \mathrm{H}), 3.90(\mathrm{~m}, 1 \mathrm{H}), 3.60(\mathrm{~m}, 1 \mathrm{H}), 1.82(\mathrm{~m}, 1 \mathrm{H}), 1.65(\mathrm{~m}, 1$ $\mathrm{H}), 1.55-1.40(\mathrm{~m}, 3 \mathrm{H}), 1.26(\mathrm{~m}, 24 \mathrm{H}), 0.88(\mathrm{t}, J=7.0 \mathrm{~Hz}, 3 \mathrm{H}) ;{ }^{13} \mathrm{C} \mathrm{NMR}\left(100 \mathrm{MHz}, \mathrm{CDCl}_{3}\right) \delta$ 159.4, 81.6, 68.0, 54.2, 41.7, 38.3, 32.1, 29.9 (4 C), 29.8 (2 C), 29.7, 29.6, 25.7, 22.9, 20.3, 14.3; 
HRMS (ESI) $\mathrm{m} / \mathrm{z}$ 328.28438. (theoretical for $\mathrm{C}_{19} \mathrm{H}_{37} \mathrm{NO}_{3}+\mathrm{H}$ : 328.28462). Anal. Calcd. for $\mathrm{C}_{19} \mathrm{H}_{37} \mathrm{NO}_{3}+0.50 \cdot \mathrm{H}_{2} \mathrm{O}$ : C, 67.81; H, 11.38; N, 4.16. Found: C 67.77; H 10.95; N 4.02\%.

(2S,3S,5R)-2-Aminooctadecane-3,5-diol (11). The benzoate ester 23 (624 mg, $1.45 \mathrm{mmol})$ and lithium hydroxide monohydrate $(380 \mathrm{mg}, 9.01 \mathrm{mmol})$ were dissolved in a mixture of ethanol and water $(10: 1,30 \mathrm{~mL})$, and the mixture was subject to microwave irradiation at $120{ }^{\circ} \mathrm{C}$ for 1.5 hours ( $\sim 3$ bar). The reaction mixture was allowed to cool to room temperature, concentrated under vacuum and diluted with $\mathrm{Et}_{2} \mathrm{O}$. The organic phase was washed with water, brine, dried over magnesium sulfate, and concentrated under vacuum. The crude product was then purified by flash chromatography $\left(\mathrm{SiO}_{2}, \mathrm{CHCl}_{3}: \mathrm{MeOH}\right.$ : ammonium hydroxide (aq., 25\%), 100:10:1) to afford 11 as a white powder (202 $\mathrm{mg}, 46 \%) . \mathrm{R}_{\mathrm{f}}=0.30$ (45:10:1 $\mathrm{CHCl}_{3}: \mathrm{MeOH}$ :ammonium hydroxide (aq. 25\%)), and 0.48 (20:5:2:1 $\mathrm{CHCl}_{3}: \mathrm{MeOH}$ :acetic acid: water); $\mathrm{mp}=63-68{ }^{\circ} \mathrm{C}$; IR $\left(v_{\max }, \mathrm{cm}^{-1}\right): 3367,3289,2917,2849,1675,1467,1378,1202,1135,1068,1018,992,841,800$, $721 ;[\alpha]^{24}{ }_{\mathrm{D}}=-12.9^{\circ}($ c $2.0, \mathrm{MeOH}),-4.83\left(\right.$ c 2.9, $\left.\mathrm{CHCl}_{3}\right) ;{ }^{1} \mathrm{H}$ NMR $\left(500 \mathrm{MHz}, \mathrm{CD}_{3} \mathrm{OD}, 60{ }^{\circ} \mathrm{C}\right) \delta$ $3.80(\mathrm{~m}, 1 \mathrm{H}), 3.72$ (dt, $J=6.8,1.6 \mathrm{~Hz}, 1 \mathrm{H}), 3.10$ (quintet, $J=6.8 \mathrm{~Hz}, 1 \mathrm{H}), 1.54(\mathrm{~m}, 2 \mathrm{H}), 1.45$ $(\mathrm{m}, 2 \mathrm{H}), 1.28(\mathrm{~m}, 22 \mathrm{H}), 1.26(\mathrm{~d}, J=5.0 \mathrm{~Hz}, 3 \mathrm{H}), 0.89(\mathrm{t}, J=6.9 \mathrm{~Hz}, 3 \mathrm{H}) ;{ }^{13} \mathrm{C} \mathrm{NMR}(75.5$ MHz, $d_{6}$-DMSO) $\delta$ 72.3, 67.7, 51.4, 40.5, 37.9, 31.6, 29.4 (7 C), 29.0, 25.4, 22.3, 17.5, 13.0; HRMS (ESI) $m / z 302.30515$ (theoretical for $\mathrm{C}_{18} \mathrm{H}_{39} \mathrm{NO}_{2}+\mathrm{H}: 302.30590$ ).

(4S,5R)-5-((S)-2-Hydroxypentadecyl)-4-methyloxazolidin-2-one (22). To a stirred solution of $(2 S, 3 R, 5 S)$-enigmol $12(263 \mathrm{mg}, 872 \mu \mathrm{mol})$ in THF $(40 \mathrm{~mL})$ was added a solution of 1,1'carbonyldiimidazole $(1.15 \mathrm{~g}, 3.81 \mathrm{~mol})$ in dry THF $(20 \mathrm{~mL})$, dropwise, at $0{ }^{\circ} \mathrm{C}$. After addition was complete, the reaction was allowed to warm to ambient temperature and the mixture was stirred for 16 hours. The reaction mixture was quenched by addition of $\mathrm{MeOH}$ and $1 \mathrm{~N} \mathrm{HCl}$ $(2 \mathrm{~mL})$. The solution was diluted with $\mathrm{Et}_{2} \mathrm{O}$, washed with the aqueous saturated sodium bicarbonate, brine, dried over magnesium sulfate, and concentrated in vacuo to give the crude product. The material was washed with hexanes to afford the product as a white solid (177 $\mathrm{mg}$, $55 \%) . \mathrm{R}_{\mathrm{f}}=0.43\left(9: 1: 1, \mathrm{CHCl}_{3}: \mathrm{MeOH}\right.$ :acetone); $\mathrm{mp}=99-101{ }^{\circ} \mathrm{C}$; IR $\left(v_{\max }, \mathrm{cm}^{-1}\right): 3345,3234$, 2954, 2919, 2848, 1734, 1716, 1466, 1417, 1392, 1380, 1235, 1101, 1067, 1055, 987, 961, 946, $746,724,665,617,572 ;[\alpha]_{\mathrm{D}}{ }^{24}=+34.0{ }^{\circ}(\mathrm{c} 1.8, \mathrm{MeOH}),+29.0^{\circ}\left(\mathrm{c} 1.7, \mathrm{CHCl}_{3}\right) ;{ }^{1} \mathrm{H} \mathrm{NMR}(400$ $\left.\mathrm{MHz}, \mathrm{CDCl}_{3}\right) \delta 4.93(\mathrm{ddd}, J=10.7,7.6,2.4 \mathrm{~Hz}, 1 \mathrm{H}), 3.96(\mathrm{~m}, 1 \mathrm{H}), 3.94(\mathrm{~m}, 1 \mathrm{H}), 2.15(\mathrm{~d}, J=$ $4.0 \mathrm{~Hz}, 1 \mathrm{H}), 1.82(\mathrm{~m}, 1 \mathrm{H}), 1.50(\mathrm{~m}, 4 \mathrm{H}), 1.24(\mathrm{~m}, 20 \mathrm{H}), 1.18(\mathrm{~d}, J=6.7 \mathrm{~Hz}, 3 \mathrm{H}), 0.86(\mathrm{t}, J=$ $7.0 \mathrm{~Hz}, 3 \mathrm{H}) ;{ }^{13} \mathrm{C} \mathrm{NMR}\left(100 \mathrm{MHz}, \mathrm{CDCl}_{3}\right) \delta 159.6,76.9,68.2,51.2,38.4,36.7,32.1,29.9$ (4 C), 29.8 (3 C), 29.6, 25.7, 22.9, 16.4, 14.3; HRMS (ESI) $\mathrm{m} / \mathrm{z} 328.28497$ (theoretical for $\mathrm{C}_{19} \mathrm{H}_{37} \mathrm{NO}_{3}+\mathrm{H}$ : 328.28462). Anal. Calcd. for $\mathrm{C}_{19} \mathrm{H}_{37} \mathrm{NO}_{3}$ : C, 69.68; H, 11.39; N, 4.28. Found: C 69.48 ; H 11.50; N 4.24\%.

(4S,5R)-5-((R)-2-Hydroxypentadecyl)-4-methyloxazolidin-2-one (26). This compound was synthesized by the method reported in literature. ${ }^{24}$ To a solution of the oxazolidinone 22 (192 mg, $568 \mu \mathrm{mol})$ in dry THF $(5 \mathrm{~mL})$ was added triphenyphosphine (466 mg, $1.76 \mathrm{mmol})$ and benzoic acid (360 mg, $2.93 \mathrm{mmol})$ at $0{ }^{\circ} \mathrm{C}$. The resulting mixture was allowed to stir at $0{ }^{\circ} \mathrm{C}$ for 15 minutes, to which diisopropyl azodicarboxylate $(610 \mu \mathrm{L}, 2.93 \mathrm{mmol})$ was added. After 3.5 hour at $0{ }^{\circ} \mathrm{C}$, the mixture was diluted with $\mathrm{Et}_{2} \mathrm{O}$, washed with the aqueous saturated sodium 
bicarbonate, brine, dried over magnesium sulfate, and concentrated in vacuo to give the crude product $(1.6 \mathrm{~g})$. This material was taken up in hexanes and filtered. The filtrate was concentrated, and the material $((R)-1-((4 S, 5 R)-4$-methyl-2-oxazolidin-5-yl)pentadecan-2-yl benzoate) 24 was dissolved in $\mathrm{MeOH}(25 \mathrm{~mL})$, to which sodium methoxide ( $3 \mathrm{~mL}, 30 \%$ solution in $\mathrm{MeOH}$ ) was added. The mixture was allowed to stir for 3 hours at room temperature, neutralized with glacial acetic acid, and concentrated under vacuum. The resulting residue was then $\operatorname{dissolved~} \mathrm{Et}_{2} \mathrm{O}$, washed with saturated sodium bicarbonate, brine, dried over magnesium sulfate and concentrated in vacuo. Purification was achieved with flash chromatography $\left(\mathrm{SiO}_{2}\right.$, hexanes: ethyl acetate) to give an off- white powder ( $85 \mathrm{mg}, 44 \%) . \mathrm{R}_{\mathrm{f}}=0.43$ (9:1:1, $\mathrm{CHCl}_{3}: \mathrm{MeOH}$ :acetone); $\mathrm{mp}=74-75$ ${ }^{\circ} \mathrm{C}$; IR $\left(v_{\max }, \mathrm{cm}^{-1}\right): 3564,3266,2916,2849,1746,1707,1472,1419,1386,1349,1259,1246$, $1229,1073,1052,1043,1022,1012,994,946,850,718,674,568 ;[\alpha]_{\mathrm{D}}{ }^{24}=+8.7^{\circ}\left(c 0.6, \mathrm{CHCl}_{3}\right)$, ${ }^{1} \mathrm{H} \mathrm{NMR}\left(400 \mathrm{MHz}, \mathrm{CDCl}_{3}\right) \delta 5.94(\mathrm{~s}, 1 \mathrm{H}), 4.78(\mathrm{~m}, 1 \mathrm{H}), 3.93(\mathrm{~m}, 1 \mathrm{H}), 3.82(\mathrm{~m}, 1 \mathrm{H}), 2.27$ (bs, $1 \mathrm{H}), 1.89(\mathrm{~m}, 1 \mathrm{H}), 1.72(\mathrm{dt}, J=14.3,3.4 \mathrm{~Hz}, 1 \mathrm{H}), 1.55-1.40(\mathrm{~m}, 3 \mathrm{H}), 1.25(\mathrm{~m}, 21 \mathrm{H})$, $1.17(\mathrm{~d}, J=6.4 \mathrm{~Hz}, 3 \mathrm{H}), 0.88(\mathrm{t}, J=7.0 \mathrm{~Hz}, 3 \mathrm{H}) ;{ }^{13} \mathrm{C} \mathrm{NMR}\left(100 \mathrm{MHz}, \mathrm{CDCl}_{3}\right) \delta 159.7,79.1$, 70.1, 51.4, 37.4, 36.5, 32.1, 29.8 (7 C), 29.6, 25.7, 22.9, 16.4, 14.3; HRMS (ESI) $\mathrm{m} / \mathrm{z} 328.28448$ (theoretical for $\mathrm{C}_{19} \mathrm{H}_{37} \mathrm{NO}_{3}+\mathrm{H}: 328.28462$ ).

(2S,3R,5R)-2-Aminooctadecane-3,5-diol (13). The oxazolidinone 26 (80 mg, $244 \mu \mathrm{mol})$ and lithium hydroxide monohydrate $(104 \mathrm{mg}, 2.48 \mathrm{mmol})$ were dissolved in a mixture of ethanol and water $(20: 3,15 \mathrm{~mL})$, and the mixture was subject to microwave irradiation at $120{ }^{\circ} \mathrm{C}$ for 1.5 hours ( $\sim 3$ bar). The reaction mixture was allowed to cool to room temperature, concentrated in vacuo and diluted with $\mathrm{Et}_{2} \mathrm{O}$. The organic phase was washed with water, brine, dried over magnesium sulfate, and concentrated in vacuo. The crude product was then purified by flash chromatography $\left(\mathrm{SiO}_{2}, 100: 10: 1 \mathrm{CHCl}_{3}\right.$ : $\mathrm{MeOH}$ : ammonium hydroxide (aq., 25\%)) to afford 13 as a white powder $(33 \mathrm{mg}, 45 \%) . \mathrm{R}_{\mathrm{f}}=0.35$ (45:10:1 $\mathrm{CHCl}_{3}: \mathrm{MeOH}$ :ammonium hydroxide (aq. $25 \%)$ ), and 0.49 (20:5:2:1 $\mathrm{CHCl}_{3}: \mathrm{MeOH}$ :acetic acid: water); $\mathrm{mp}=80-82{ }^{\circ} \mathrm{C}$; IR $\left(\mathrm{CDCl}_{3}\right.$ solution, $\left.v_{\max }, \mathrm{cm}^{-1}\right)$ : 3450, 2890, 2820, 1690, 1470, 1370, 1325, 1200, 1085, 1060, 1030, 1010; $[\alpha]^{24}{ }_{\mathrm{D}}=+9.3^{\circ}(c$ 1.7, MeOH$),+4.1^{\circ}\left(c\right.$ 1.7, $\left.\mathrm{CHCl}_{3}\right) ;{ }^{1} \mathrm{H}$ NMR $\left(500 \mathrm{MHz}, d_{6}-\mathrm{DMSO}, 80{ }^{\circ} \mathrm{C}\right) \delta$ $3.63(\mathrm{~m}, 1 \mathrm{H}), 3.40$ (quintet, $J=4.1 \mathrm{~Hz}, 1 \mathrm{H}), 3.07(\mathrm{~m}, 4 \mathrm{H}), 2.71(\mathrm{ddd}, J=6.6,4.6,1.9 \mathrm{~Hz}, 1 \mathrm{H})$ $1.50(\mathrm{dt}, J=14.0,3.9 \mathrm{~Hz}, 1 \mathrm{H}), 1.39(\mathrm{dd}, J=14.0,8.1 \mathrm{~Hz}, 1 \mathrm{H}), 1.38(\mathrm{~m}, 4 \mathrm{H}), 1.26(\mathrm{~m}, 20 \mathrm{H})$, $0.92(\mathrm{~d}, J=6.5 \mathrm{~Hz}, 3 \mathrm{H}), 0.86(\mathrm{t}, J=6.8 \mathrm{~Hz}, 3 \mathrm{H}) ;{ }^{13} \mathrm{C} \mathrm{NMR}\left(75.5 \mathrm{MHz}, \mathrm{CDCl}_{3}\right) \delta 74.5,71.7$, 50.7, 38.3, 37.5, 31.9, 29.7, 29.5 (5 C), 29.4 (2 C), 25.6, 22.7, 16.8, 14.1; HRMS (ESI) m/z 302.30449 (theoretical for $\mathrm{C}_{18} \mathrm{H}_{39} \mathrm{NO}_{2}+\mathrm{H}: 302.30590$ ).

\section{Acknowledgements}

We thank the National Cancer Institute (NCI) for a National Cooperative Drug Discovery Groups (NCDDG) grant (U19-CA87525) and the Emory Institute for Drug Discovery (EIDD) for funding and consultation. We also would like to thank Dr. Claney Pereira (Emory University) for his assistance with NMR studies. 


\section{References and Notes}

1. (a) Cuvillier, O.; Pirianov, G.; Kleuser, B.; Vanek, P. G.; Coso, O. A.; Gutkind, J. S.; Spiegel, S. Nature 1996, 381, 800. (b) Takabe, K.; Paugh, S. W.; Milstien, S.; Spiegel, S. Pharmacol Rev. 2008, 60, 181.

2. Menaldino, D. S.; Bushnev, A.; Sun, A.; Liotta, D. C.; Symolon, H.; Desai, K.; Dillehay, D. L.; Peng, Q.; Wang, E.; Allegood, J.; Trotman-Pruett, S.; Sullards, M. C.; Merrill, A. H. Jr. Pharmacol. Res. 2003, 47, 373.

3. (a) Kester, M.; Kolesnick, R. Pharmacol. Res. 2003, 47, 365. (b) Zeidan, Y. H.; Hannun, Y. A. Trends. Mol. Med. 2007, 13, 327.

4. Kappos, L.; Antel, J.; Comi, G.; Montalban, X.; O'Connor, P.; Polman, C. H.; Haas, T.; Korn, A. A.; Karlsson, G.; Radue, E. W. N. Engl. J. Med. 2006, 355, 1124.

5. Jatoi, A.; Suman, V. J.; Schaefer, P.; Block, M.; Loprinzi, C.; Roche, P.; Garneau, S.; Morton, R.; Stella, P. J.; Alberts, S. R.; Pittelkow, M.; Sloan, J.; Pagano, R. Breast Cancer Res. Treat. 2003, 80, 99.

6. Marasas, W. F. O.; Nelson, P. E.; Toussoun, T. A. “Toxigenic Fusarium Species. Identity and Mycotoxicology." Pennsylvania State University Press, University Park, Pittsburgh, 1984, $\mathrm{p} 216$.

7. Wang, E.; Norred, W. P.; Bacon, C. W.; Riley, R. T.; Merrill, A. H. Jr. J. Biol. Chem. 1991, 266, 14486.

8. (a) Desai, K.; Sullards, M. C.; Allegood, J.; Wang, E.; Schmelz, E. M.; Hartl, M.; Humpf, H. U.; Liotta, D. C.; Peng, Q.; Merrill, A. H. Jr. Biochimica et Biophysica Acta-Molecular and Cell Biology of Lipids 2002, 1585, 188. (b) Merrill, A. H. Jr.; Sullards, M. C.; Wang, E.; Voss, K. A.; Riley, R. T. Environ Health Perspect. 2001, 109, 283.

9. Menaldino, D. S. Ph.D. Thesis, Emory University, 1992.

10. (a) Lagu, B. R.; Liotta, D. C. Tetrahedron Lett. 1994, 35, 547. (b) Lagu, B. R.; Crane, H. M.; Liotta, D. C. J. Org. Chem. 1993, 58, 4191. (c) Lagu, B. R.; Liotta, D. C. Tetrahedron Lett. 1994, 35, 4485. (d) Goh, J. B.; Lagu, B. R.; Wuster, J.; Liotta, D. C. Tetrahedron Lett. 1994, $35,6029$.

11. (a) Wiseman, J. M.; McDonald, F. E.; Liotta, D. C. Org. Lett. 2005, 7, 3155 (Addition and Correction: Wiseman, J. M.; McDonald, F. E.; Liotta, D. C. Org. Lett. 2007, 9, 2959). (b) Saikia, P. P.; Goswami, A.; Baishya, G.; Barua, N. C. Tetrahedron Lett. 2009, 50, 1328. (c) Dias, L. C.; Fattori, J.; Perez, C. C. Tetrahedron Lett. 2008, 49, 557. (d) Dias, L. C.; Fattori, J.; Perez, C. C.; de Oliveira, V. M.; Aguilar, A. M. Tetrahedron 2008, 64, 5891.

12. Yim, A. S. Y.; Wills, M. Tetrahedron 2005, 61, 7994.

13. The optical rotation we observed for $\mathbf{1 1}$ did not agree with the literature. The synthesis of compound $\mathbf{1 1}$ has recently been reported by Saikia et al. ${ }^{11 \mathrm{c}}$ Their reported optical rotation is in agreement with Wiseman et al. ${ }^{11 a} \mathrm{~A}$ subsequently published correction to this paper indicated that the original structural assignment for $\mathbf{1 1}$ was incorrect. 
14. (a) To simplify the discussion, we kept the numbering of carbon atoms in oxazolidinones the same as the parent enigmols. (b) While attempting to determine relative stereochemistry between $\mathrm{C} 2$ and $\mathrm{C} 3$ by NOE in the oxazolidinones $(\mathbf{2 1}, \mathbf{2 2}, \mathbf{2 5}, \mathbf{2 6})$, we observed that the exocyclic methyl group appeared as a doublet at $\sim 1.18 \mathrm{ppm}$ in the $(2 S, 3 S)$ trans-

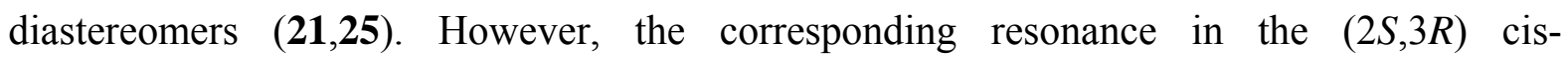
diastereomers $(\mathbf{2 2 , 2 6 )}$ was obscured by the large alkyl chain signal at $1.26 \mathrm{ppm}$.

15. Hoyle, T. R.; Jeffry, C. S.; Shao, F. Nat. Protoc. 2007, 2, 2451.

16. Mosher ester of the $5 S$ - derivatives of 21 and 22 showed $\Delta \delta^{\mathrm{SR}}=+0.33$ and +0.80 respectively. Mosher ester of the $5 R$ - derivatives of 25 and 26 showed $\Delta \delta^{\mathrm{SR}}=-0.37$ and 0.16 respectively.

17. Rychnovsky, S. D.; Skalitzky, D. J. Tetrahedron Lett. 1990, 31, 945. To summarize Rychnovsky's findings, the acetonide of syn-1,3 diols show a chemical shift of the quaternary carbon below $100 \mathrm{ppm}$ and the two methyl groups at 30 and $20 \mathrm{ppm}$, while the anti-1,3 diols show a chemical shift of the quaternary carbon above $100 \mathrm{ppm}$ and the two methyl groups near 25 ppm.

18. Dix, D.; Imming, P. Arch. Pharm.1995, 328, 203.

19. Camps, P.; Perez, F.; Soldevilla, N.; Borrego, M. A. Tetrahedron Asym. 1999, 10, 493.

20. Skiles, J. W.; Miao, C.; Sorcek, R.; Jacober, S.; Mui, P. W.; Chow, G.; Weldon, S. M.; Possanza, G.; Skoog, M. J. Med. Chem. 1992, 35, 4795.

21. Hoffmann, R. W.; Ruehl, T.; Chemla, F.; Zahneisen, T.; Liebig’s Ann. Chem. 1992, 719.

22. Sbardella, G.; Castellano, S.; Vicidomini, C.; Rotili, D.; Nebbioso, E.; Miceli, M.; Altucci, L.; Mai, A. Bioorg. Med. Chem. Lett. 2008, 18, 2788.

23. Optical rotation reported here was obtained from purifying a small portion by chromatography $\left(\mathrm{SiO}_{2}\right.$, hexanes: ethyl acetate, both containing $2 \%$ triethylamine). The reported value is for initial fractions only as later fractions displayed lower values (due to slow racemization on the column). See Discussion for details.

24. Nakamura, Y.; Hirai, M.; Tamotsu, K.; Yonezawa, Y.; Shin, C. G. Bull. Chem. Soc. Jpn. 1995, 68, 1369. 